\title{
Dramatic diurnal variation in the concentration of the human trefoil peptide TFF2 in gastric juice
}

\author{
J I Semple, J L Newton, B R Westley, F E B May
}

\begin{abstract}
Background-TFF2, a member of the trefoil factor family of proteins, is a glycosylated protein of 106 amino acids. It is secreted by gastric antral and pyloric glands and by Brunner's glands of the duodenum. TFF2 is found in high concentrations around sites of ulceration. It stimulates cell motility and is probably the principal cytoprotective trefoil peptide in the stomach.
\end{abstract}

Aims-To determine if production of TFF2 follows a circadian rhythm and to measure changes in secretion of TFF2 in response to food intake and during sleep.

Subjects-Young healthy adults were recruited. They were asymptomatic and were not receiving medication. The 24 hour regimen was designed to allow normal stimulation of gastric secretion in response to food intake and sleep. Gastric juice was collected two hourly via a nasogastric tube.

Methods-Glycosylated and nonglycosylated TFF2 proteins were measured by quantitative western transfer analysis. The results were analysed statistically using SPSS software.

Results-There was a dramatic diurnal variation in the concentration of TFF2. The mean concentration was lowest in the early evening $(0.29 \mu \mathrm{g} / \mathrm{ml})$, increased gradually during the evening, and then sharply during the night to reach 7.9 $\mu \mathrm{g} / \mathrm{ml}$. The ratio of glycosylated to nonglycosylated TFF2 varied and was higher during the night than in the afternoon. pH, total protein, and pepsin concentrations in gastric juice did not vary significantly over 24 hours.

Conclusion-The data suggest that diurnal variations in TFF2 secretion occur independently of pepsin and gastric acid secretion. The concentration of glycosylated TFF2 in the gastric lumen falls in response to food intake. TFF2 secretion increases during inactivity and sleep. These results suggest that secretion of TFF 2 in the stomach is highest during the night and that the cytoprotective effects of TFF 2 on the gastric mucosa occur mainly during sleep.

(Gut 2001;48:648-655)

Keywords: trefoil protein; human TFF2; gastric acid; diurnal; pepsin; circadian rhythm

TFF2, originally called human spasmolytic polypeptide, was the second member of the human family of trefoil peptides to be identified. ${ }^{1}$ There are three human trefoil proteins whose genes are clustered on chromosome 21 , with TFF1 $12.5 \mathrm{~kb}$ upstream of TFF2 which is $\sim 30 \mathrm{~kb}$ upstream of TFF3. ${ }^{23}$ Trefoil peptides are small secreted proteins characterised by a conserved domain of 42-43 amino acid residues. ${ }^{3-6}$ The six conserved cysteine residues of the trefoil domain form three intramolecular disulphide bonds and hence three loops that are stacked in a characteristic structure..$^{7-10}$ Mature TFF2, which is a $12 \mathrm{kDa}$ protein of 106 amino acids, contains two trefoil domains separated by a short sequence of seven residues (see fig 1A). ${ }^{1}$ Both $x$ ray crystallography and solution nuclear magnetic resonance ${ }^{7-9}$ have been used to solve the structure of the porcine homologue of TFF2. It consists of two compact globular domains that adopt the same tertiary structure, joined via a small interface.

Trefoil peptides are expressed in a site specific manner in the gastrointestinal tract and human TFF2 is concentrated in the stomach and duodenum. The cellular distribution of human TFF2 mRNA in the stomach has been characterised by in situ hybridisation. ${ }^{11}$ Human TFF 2 mRNA is present in the cardiac glands, in rare glands at the base of the gastric body mucosa, and in large amounts in the pyloric glands. ${ }^{11}$ Human TFF2 protein is present in the glands at the base of normal gastric antral mucosa and in Brunner's glands of the duodenum. ${ }^{11}$

The first indications of the biological role of trefoil peptides came from immunohistochemical and in situ hybridisation studies of their expression in various pathologies of the gastrointestinal tract. ${ }^{12}$ High concentrations of TFF2 mRNA are found in cells adjacent to sites of mucosal injury in the duodenum, small intestine, and colon. ${ }^{13}$ This ectopic expression suggested that trefoil peptides have a role in tissue repair..$^{3-612}$ Following acute mucosal injury, repair of the mucosa of the gastrointestinal tract is initiated within a few minutes. One of the earliest processes is rapid migration of cells from the margins of the damaged region over the denuded area to re-establish epithelial continuity, a process called epithelial restitution. The possibility that trefoil peptides stimulate this migration was suggested by the observation that TFF2 was motogenic for cells in culture. Recombinant $\mathrm{TFF} 2^{14}$ stimulated human colonic carcinoma cells to migrate across and invade into collagen gel, ${ }^{15}$ and stimulated their migration across plastic in an in vitro assay of wound repair. ${ }^{15}{ }^{16}$ TFF2 may be of particular importance among the trefoil peptides in the repair process as it is produced 
within 30 minutes after cryoprobe induction of gastric ulceration in the rat. ${ }^{17}$

Studies with recombinant human $\mathrm{TFF} 2^{14}$ have shown that TFF2 protects rats both from indomethacin and restraint induced, and from ethanol induced gastric mucosal damage. ${ }^{15} 1819$ Further evidence for the protective role of $\mathrm{TFF} 2$ is provided by the demonstration from Ussing chamber experiments that TFF2 reduces proton permeation through gastric mucus in vitro and in vivo. ${ }^{20}$ It has also been suggested that the normal role of trefoil peptides may be to maintain the integrity of the gastrointestinal epithelial layer. ${ }^{3-6}$

We have shown recently that significant quantities of $12 \mathrm{kDa}$ TFF2 are present in human gastric juice. ${ }^{21}$ Larger quantities of a protein of higher apparent molecular mass were also detected. This was shown to be $N$-glycosylated TFF2, glycosylated on $\mathrm{Asn}^{15}$ which forms part of the single $N$-glycosylation consensus site in the TFF2 protein (fig 1A). The majority of human TFF2 present in gastric mucosa is glycosylated. ${ }^{21}$ Glycosylation may be of functional importance and it has been shown that glycosylated recombinant $\mathrm{TFF} 2$ is more potent than the non-glycosylated protein in protection against indomethacin induced gastric damage in vivo. ${ }^{15}$

Secretion by gastric cells of acid, pepsin, intrinsic factor, and gastrointestinal regulatory peptides is tightly regulated. Acid and pepsin are secreted following food intake while secretion of other proteins follows a circadian pattern. In the present study, $\mathrm{TFF} 2$ protein has been quantified in gastric juice collected from young healthy subjects over a 24 hour time period. Meals were standardised to allow measurement of changes in TFF2 levels in response to food intake. The changes in TFF 2 concentrations were related to $\mathrm{pH}$, and to total protein and pepsin concentrations in gastric juice.

\section{Methods}

COLLECTION OF GASTRIC JUICE SAMPLES

Twelve volunteers aged 20-24 years (mean age 21) were recruited into the study. Four were female and eight were male. All volunteers were asymptomatic, were not receiving medication, and had no significant past medical history. They were all non-smokers. All volunteers gave written informed consent. Ethics permission for the study was obtained from the joint Newcastle/University of Newcastle upon Tyne ethics committee.

Volunteers fasted for 12 hours prior to initiation of the collection of gastric juice. They attended the observation unit for 24 hours. The 24 hour regimen was designed to resemble the natural situation with normal stimulation of gastric secretion in response to food intake. Each individual had a $12 \mathrm{~F}$ Ryles nasogastric tube (RT 2012, Pennine Healthcare, UK) inserted via the anterior nares without lubrication at 8:00 am. The position of the tube in the dependent part of the stomach was determined by the water recovery method. ${ }^{22}$ Volunteers drank $20 \mathrm{ml}$ of water, which was then recovered by aspiration. The first sample was collected at 9:00 am, 45 minutes after correct positioning of the tube. A total of 12 samples of gastric juice were collected: the first at 9:00 am and the last at 7:00 am the following day. The nasogastric tube was removed at 7:15 am. Meals were standardised to ensure comparable intake of protein and were taken at $1: 15 \mathrm{pm}$ and 5:15 pm immediately after aspiration of the preceding sample. The volunteers were allowed to drink clear fluids during the 30 minutes following aspiration of each sample and therefore had not taken liquid for at least 1.5 hours prior to aspiration of the succeeding sample. As gastric emptying is accomplished within one hour, this ensured that intake of liquid did not compromise the results obtained. ${ }^{22}$ No alcohol consumption was permitted. The volunteers went to bed at $11: 30 \mathrm{pm}$ and were all asleep at 1:00 am.

Samples of gastric juice were aspirated via the nasogastric tube using a $20 \mathrm{ml}$ sterile syringe at two hourly intervals. Samples were filtered to remove particulate material. This did not affect the TFF2 concentration The $\mathrm{pH}$ of each sample was measured and $1 \mathrm{ml}$ of each sample was then diluted 10-fold with $55 \mathrm{mM}$ sodium chloride, $55 \mathrm{mM}$ sodium acetate, and acetic acid, $\mathrm{pH} 4.1$, to inactivate but not denature pepsin. This stabilises both TFF2 and pepsin and does not interfere with the subsequent assay of either protein. Each diluted sample of gastric juice was divided into four aliquots for storage at $-20^{\circ} \mathrm{C}$.

\section{MEASUREMENT OF TFF2}

Aliquots of diluted gastric juice were passed into sterile water by gel filtration over Sephadex G25 (Pharmacia) and concentrated by vacuum evaporation. Samples were electrophoresed on polyacrylamide gels that contained $0.1 \%$ sodium dodecyl sulphate as described previously. ${ }^{23}$ The stacking gels contained $10 \%(\mathrm{w} / \mathrm{v})$ acrylamide, the separating gels contained $20 \%$ $(\mathrm{w} / \mathrm{v})$ acrylamide, and both contained 10\% glycerol. Samples to be fractionated were brought to $62.5 \mathrm{mM}$ Tris $\mathrm{HCl}, \mathrm{pH} 6.8,12.5$ mM EDTA, $100 \mathrm{mM} \beta$-mercaptoethanol, and $0.005 \%$ bromophenol blue and boiled for five minutes prior to loading. Molecular weight markers and recombinant TFF2 were included in all gels.

The separated proteins were transferred from the gels to $0.2 \mu \mathrm{m}$ pore size PVDF membranes (Schleicher and Schuell) using a semi dry transfer apparatus (Schleicher and Schuell) for 15 minutes at $100 \mathrm{~mA}$, and left uncovered at room temperature overnight. They were fixed in $0.2 \%$ glutaraldehyde for 45 minutes, blocked with $3 \%(\mathrm{w} / \mathrm{v})$ bovine serum albumin in phosphate buffered saline for one hour at $37^{\circ} \mathrm{C}$, and incubated with a $1: 1000$ dilution of mouse polyclonal anti-TFF2 antiserum in 3\% $(\mathrm{w} / \mathrm{v})$ bovine serum albumin and phosphate buffered saline for two hours at $37^{\circ} \mathrm{C}$. The mouse antisera was raised against the corrected 16 amino acid carboxy terminal peptide EVPWCFFPKSVEDCHY of human TFF2 (see fig 1A) conjugated to keyhole limpet haemocyanin. ${ }^{21}$ The membranes were incubated for a further two hours at $37^{\circ} \mathrm{C}$ with alkaline phosphatase conjugated rabbit antimouse IgG in phosphate buffered saline containing $0.1 \%$ 


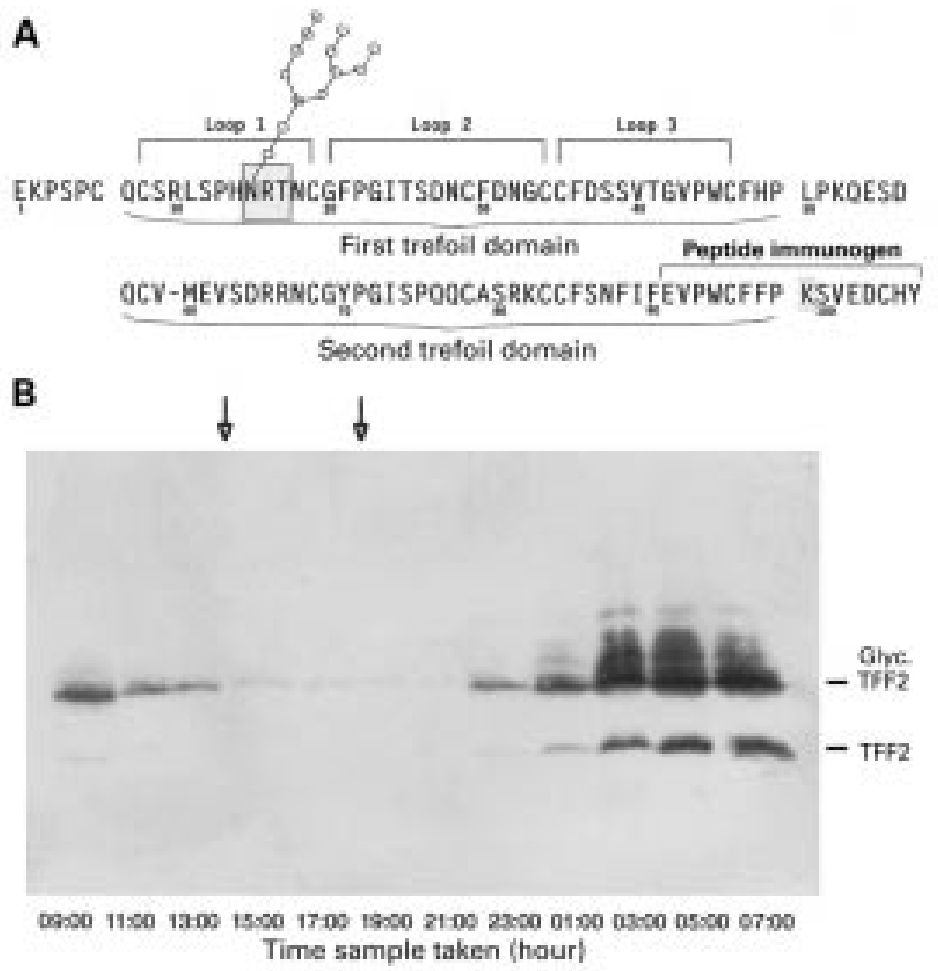

Figure 1 Detection of TFF2 protein in gastric juice over 24 hours. (A) Modified sequence of the mature TFF2 protein. The positions of the two trefoil domains are indicated, as are the amino acids included in each of the three loops formed during folding of the trefoil domains. The single $N$-glycosylation recognition sequence, which is a potential glycosylation site located in loop 1 of the first trefoil domain, is boxed. The lysine residue $(K)$ which replaces the asparagine residue found in the previously published sequence $e^{1}$ at position 99 is also boxed. The 16 amino acid peptide synthesised for use as an immunogen is also indicated. Spaces have been inserted in the sequence after residues 6, 49, and 98 to indicate the limits of the trefoil domains. (B) Human gastric juice was collected at two hourly intervals over a 24 hour time course from a young volunteer. Aliquots were subjected to electrophoresis on a denaturing polyacrylamide gel, transferred to PVDF membranes, and reacted with TFF2 antisera as described in the methods section. Downward pointing arrows indicate meal times. The positions of glycosylated TFF2 (Glyc. TFF2) and

non-glycosylated TFF2 (TFF2) are shown on the right hand side.

Tween 20 and developed as described previously. ${ }^{21} 24$

The intensities of the TFF2 immunoreactive protein bands were measured using image analysis. Preliminary experiments demonstrated that the intensity of the protein band detected was proportional to the amount of recombinant protein loaded on the gel. The amount of TFF2 protein in the gastric juice samples was determined by comparison with the reaction of standards of known amounts of glycosylated and non-glycosylated recombinant TFF2 included on the gel, as described previously. ${ }^{21}$

MEASUREMENT OF PEPSIN ACTIVITY IN, TOTAL PROTEIN CONTENT OF, AND pH OF GASTRIC JUICE

Samples were assayed for pepsin activity within two weeks of collection. Pepsin activity was assessed by an amino terminal assay at $\mathrm{pH} 2.2$, with succinyl albumin as the substrate and porcine pepsin as the standard. ${ }^{25}$ Protein concentrations of gastric juice samples were measured using the bicinchoninic acid protein assay. ${ }^{26}$ Prior to dilution with sodium acetate buffer, the $\mathrm{pH}$ of each sample of gastric juice was measured.

Data were analysed using SPSS software. Paired sample statistics were used for analysis of the data shown in figs $2-4$, fig 6 , and table 1 .
Parametric and non-parametric statistical tests were used for analysis of the data shown in fig 7 , as detailed in the text.

\section{Results}

MEASUREMENT OF GLYCOSYLATED AND

NON-GLYCOSYLATED TFF2 IN GASTRIC JUICE

To detect human TFF2 in the gastric juice samples, proteins from equal volumes of each sample were separated by denaturing polyacrylamide gel electrophoresis, transferred to PVDF membranes, and reacted with antiserum as described in the methods section. An example of the results obtained for one of the 12 individuals is shown in fig $1 \mathrm{~B}$. Two major TFF2 immunoreactive protein bands were detected. The heterogeneous protein that migrates more slowly with an apparent molecular weight of $\sim 20 \mathrm{kDa}$ has been shown previously to be mature secreted TFF2 that is glycosylated via an $N$-linkage on the first asparagine in loop 1 (fig $1 \mathrm{~A}$ ). ${ }^{21}$ The less prominent protein that migrates faster, has an apparent molecular weight of $12 \mathrm{kDa}$, and comigrates with recombinant $\mathrm{TFF} 2$ is unmodified mature TFF2. ${ }^{21}$ Glycosylated TFF2 was detected in a higher proportion of the samples than non-glycosylated TFF2.

Figure 1B shows that there was a dramatic variation in the concentration of TFF 2 present in the gastric juice of an individual over 24 hours. TFF2 concentrations were lowest during the afternoon and early evening and rose during the night to reach their highest concentrations in the early morning. The amount of TFF2 detected in the first samples, and for some individuals in the second samples, of gastric juice may have been reduced due to dilution of the gastric contents by the method used to position the nasogastric tube. This involved volunteers drinking $20 \mathrm{ml}$ of water, which was then aspirated from the stomach.

The amounts of glycosylated and nonglycosylated TFF2 in the gastric juice samples of the 12 individuals were quantified by comparison with known amounts of glycosylated and non-glycosylated recombinant TFF $2 .{ }^{21}$ Mean (SEM) concentrations of glycosylated and non-glycosylated TFF2 in the gastric juice samples for the 12 volunteers are shown in fig 2. The concentration of glycosylated TFF2 recovered during the morning but then fell to reach its lowest mean concentration at 7:00 pm. Subsequently it rose, at first gradually and then sharply, to reach a maximum mean concentration of approximately $6 \mu \mathrm{g} / \mathrm{ml}$ at 5:00 am. The mean concentration of non-glycosylated TFF2 was much lower (below $0.1 \mu \mathrm{g} / \mathrm{ml}$ ) during the morning, barely detectable during the afternoon and evening, but rose dramatically during the early hours of the morning. The concentration of glycosylated TFF2 became significantly higher $(p=0.004)$ than the concentration of glycosylated TFF2 present in the gastric juice at 7:00 pm by $11.00 \mathrm{pm}$. The concentration of non-glycosylated TFF2 also became significantly higher $(\mathrm{p}=0.046)$ at 11:00 $\mathrm{pm}$. 


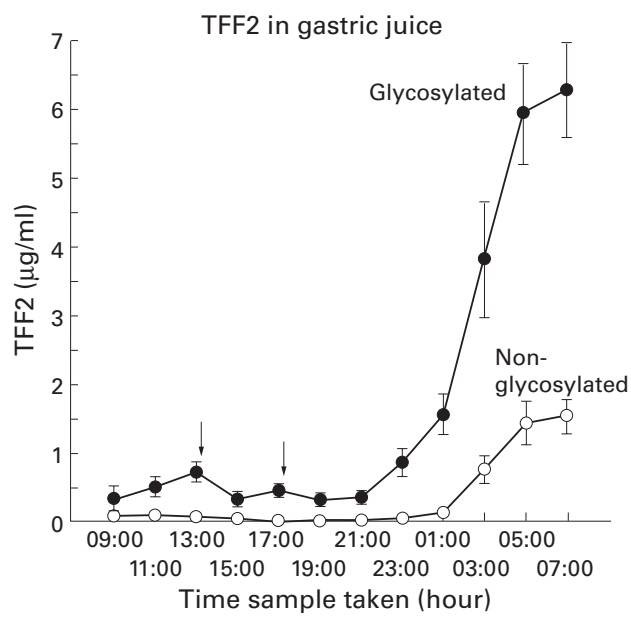

Figure 2 Concentration of glycosylated TFF2 and non-glycosylated TFF2 in normal human gastric juice over a 24 hour period. Gastric juice was collected from 12 healthy volunteers at two hourly intervals for 24 hours and concentrations of TFF2 were measured as described in the methods. Mean (SEM) concentrations of glycosylated TFF2 and non-glycosylated TFF2 are shown. Downward pointing arrows indicate meal times.

CAUSES OF CHANGES IN TFF2 CONCENTRATION AND INDIVIDUAL VARIABILITY

Levels of glycosylated, non-glycosylated, and total TFF2 rose dramatically between 9:00 pm and 5:00 am (fig 2). Glycosylated TFF2 rose from $0.29(0.09)$ to $5.91 \quad(0.73) \mu \mathrm{g} / \mathrm{ml}$ $(\mathrm{p}<0.0001)$, non-glycosylated TFF2 rose from undetectable levels to $1.4 \quad(0.3) \quad \mu \mathrm{g} / \mathrm{ml}$ $(\mathrm{p}=0.002)$, and total TFF2 rose from 0.29 (0.09) to $7.32(1.02) \mu \mathrm{g} / \mathrm{ml}(\mathrm{p}<0.0001)$. The initial more gradual increases in TFF2 concentrations occurred between 7:00 pm and 11:00 $\mathrm{pm}$ while volunteers were resting and the more dramatic increases occurred between 1:00 am and 5:00 am while they were asleep.

Concentrations of glycosylated and nonglycosylated TFF2 rose during the night in all 12 individuals but there was considerable variation both in TFF 2 concentration and in the extent of the increase. TFF2 concentrations were highest in one individual at 3:00 am, in five individuals at 5:00 am, and in six individuals at 7:00 am. The extent of variation is illustrated in fig 3 which shows TFF2 concentrations in gastric juice at 7:00 pm and 7:00 am. Concentrations of TFF2 in gastric juice at 7:00 am varied between individuals from 2.38 to $10.2 \mu \mathrm{g} / \mathrm{ml}$ for glycosylated TFF2 and from 0.56 to $3.2 \mu \mathrm{g} / \mathrm{ml}$ for non-glycosylated TFF2.

Figure 3 also illustrates the extent of the variation in the increase in gastric luminal TFF 2 concentration that occurred between individuals. The concentration of glycosylated TFF2 increased between threefold and 250fold. The increase in total TFF 2 concentration in the gastric juice that occurred during sleep was between 3.7-fold and 340-fold.

The data shown in fig $1 \mathrm{~B}$ and fig 2 suggest that there may be a decrease in TFF2 concentration following food intake, which occurred at $1: 15 \mathrm{pm}$ and $5: 15 \mathrm{pm}$. Concentrations of glycosylated $\mathrm{TFF} 2$ and total $\mathrm{TFF} 2$ were significantly lower following lunch (table 1). Very little non-glycosylated TFF2 was detected at these times and the decreases after each meal

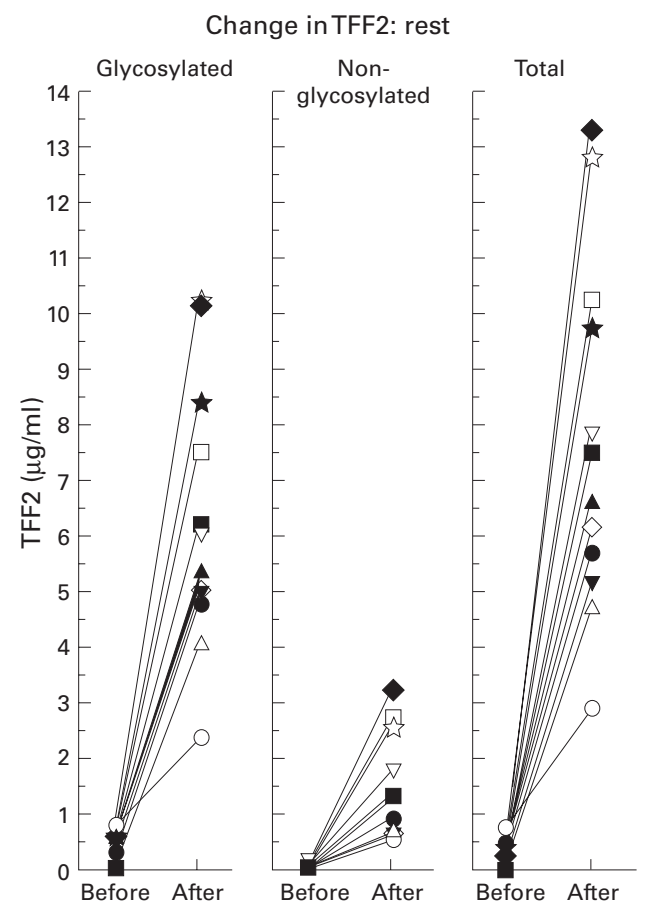

Figure 3 Effect of sleep on gastric luminal TFF2 concentrations. Gastric juice was collected from 12 healthy volunteers in the early evening at 7:00 pm and after they woke at 7:00 am. Concentrations of glycosylated TFF2, non-glycosylated TFF2, and total TFF2 concentrations were measured as described in the methods. The values obtained for all volunteers are shown.

were not significant. The decreases in glycosylated and total TFF2 following supper were statistically significant (table 1). Emptying of the liquid phase after food consumption occurs within 45 minutes $^{22}$ and it is unlikely that the reduction in TFF2 concentration following food intake is a dilution effect. This suggests that ingestion of food may suppress TFF2 secretion.

Mean TFF2 concentrations mask considerable variability both in TFF2 concentrations and the effect of food intake. The changes induced in each of the 12 volunteers by food ingestion are illustrated in fig 4. After lunch, total TFF2 concentration decreased in nine subjects between twofold and 10.5-fold, with TFF2 becoming undetectable in one individual, and increased in three subjects between 1.3-fold and 1.6-fold. After the second meal, TFF2 concentrations fell in eight subjects between 1.3-fold and 7-fold, with TFF2 becoming undetectable in three individuals, remained unchanged in three individuals, and rose in only one subject 1.2 -fold.

RATIO OF GLYCOSYLATED AND

NON-GLYCOSYLATED TFF2

We have reported previously that the ratio of glycosylated TFF2 to non-glycosylated TFF2 in gastric juice varies between 5:1 and 10:1. The possibility that this ratio may change during the day was considered. As shown in fig 5, the means of the relative proportions of glycosylated and non-glycosylated TFF2 changed 
Table 1 Effect of food intake on mean TFF2 concentrations in gastric juice

\begin{tabular}{lllll}
\hline Meal & Time & Glyc. TFF2 $(\mu \mathrm{g} / \mathrm{ml})$ & TFF2 $(\mu \mathrm{g} / \mathrm{ml})$ & Total TFF2 $(\mu \mathrm{g} / \mathrm{ml})$ \\
\hline Lunch & $1: 00 \mathrm{pm}$ & $0.72(0.14)$ & $0.08(0.27)$ & $0.8(0.16)$ \\
& $3: 00 \mathrm{pm}$ & $0.32(0.10)$ & $0.05(0.04)$ & $0.37(0.13)$ \\
& & $\mathrm{p}=0.04$ & $\mathrm{p}=0.38$ & $\mathrm{p}=0.05$ \\
Supper & $5: 00 \mathrm{pm}$ & $0.45(0.08)$ & $0.02(0.01)$ & $0.47(0.08)$ \\
& $7: 00 \mathrm{pm}$ & $0.29(0.09)$ & $0(0)$ & $0.29(0.09)$ \\
& & $\mathrm{p}=0.025$ & $\mathrm{p}=0.167$ & $\mathrm{p}=0.017$
\end{tabular}

Gastric juice was collected 15 minutes before and one hour and 45 minutes after both lunch and supper. Concentrations of glycosylated TFF2 (Glyc. TFF2), non-glycosylated TFF2 (TFF2), and total TFF2 were measured.

Mean (SEM) values are shown.

Significant differences were tested using the paired sample $t$ test.

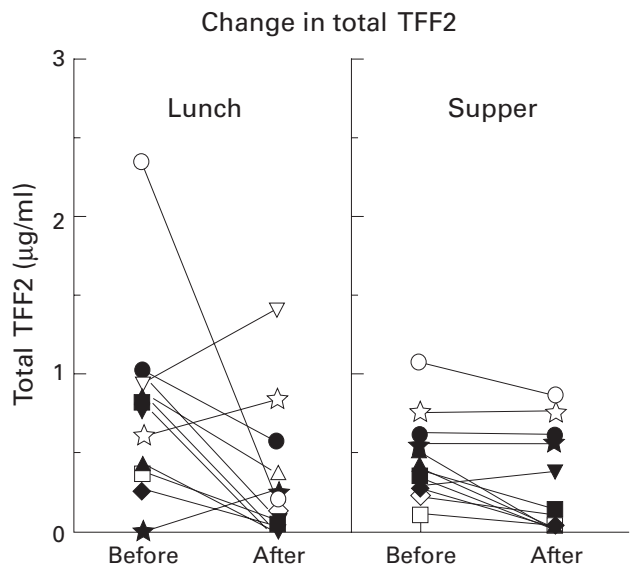

Figure 4 Effect of eating on gastric luminal TFF2 concentrations. Gastric juice was collected from 12 healthy volunteers 15 minutes before and one hour and 45 minutes after both lunch and supper. Total TFF2 concentrations were measured as described in the methods. Values obtained for all volunteers are shown.

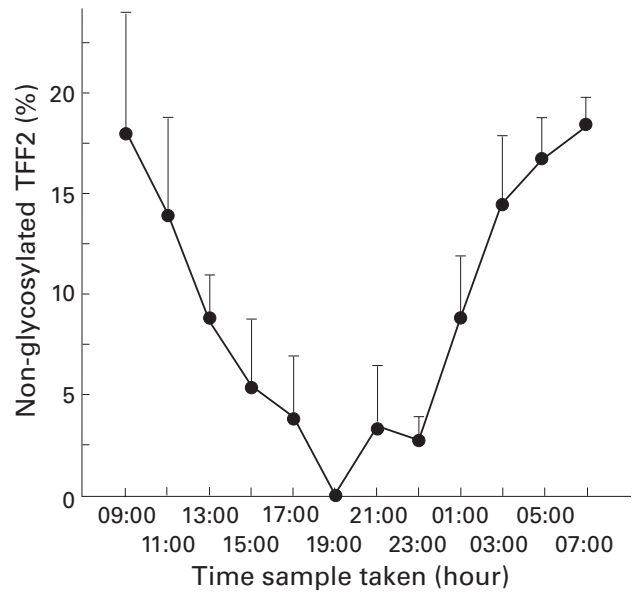

Figure 5 Proportion of TFF2 that is not glycosylated. Gastric juice was collected from 12 healthy volunteers at two hourly intervals for 24 hours and concentrations of TFF2 were measured as described in the methods. Mean (SEM) percentages of the total TFF2 that was not glycosylated are shown.

during the 24 hours of the study. The relationship is expressed as the percentage of nonglycosylated TFF2 because when nonglycosylated TFF2 is undetectable it is not possible to calculate the ratio of the two proteins.

It is noteworthy that the proportion of nonglycosylated protein is significantly higher during the night and early morning. At the start of the 24 hour study, the percentage of nonglycosylated TFF2 was approximately $15 \%$.
During late morning and afternoon, the percentage of non-glycosylated TFF2 fell to reach $0 \%$ at 7:00 pm. The proportion of nonglycosylated TFF2 present at 1:00 pm was still significantly higher than the proportion at 7:00 $\mathrm{pm}(\mathrm{p}=0.002)$ and the proportion became significantly higher again at 1:00 am $(p=0.003)$. Thereafter the percentage of non-glycosylated TFF 2 rose to reach approximately $15 \%$ again by 3:00 am $(p<0.0001)$. The ratio of glycosylated TFF2 to non-glycosylated TFF2 at 7:00 am, when non-glycosylated TFF2 concentrations were highest, varied between 2.7:1 and $7: 1$.

MEASUREMENT OF TOTAL PROTEIN

The possibility that the concentration of human TFF2 in gastric juice (fig 6A) reflects changes in overall protein concentration over 24 hours was considered. Mean (SEM) protein concentrations in the gastric juice from the 12 individuals at each time point are shown in fig $6 \mathrm{~B}$. The lower protein concentration in the first sample is caused by the procedure used to insert the nasogastric tube. By 1:00 pm, mean protein concentration was $2.22(0.32) \mathrm{mg} / \mathrm{ml}$, and for the remainder of the study it varied little and stayed within the range 2.45-3.42 $\mathrm{mg} / \mathrm{ml}$. There were no significant increases in protein concentration after the first or second meal (fig 6B).

Comparison of mean concentrations of total TFF2 in gastric juice over the 24 hours (fig 6A) with mean concentrations of total protein (fig 6B) demonstrated clearly that the concentration of TFF 2 changed independently of total protein concentration. This implies that the increase in TFF 2 concentration in gastric juice results from active specific $\mathrm{TFF} 2$ secretion and does not reflect general secretory activity. The mean concentration of TFF2 in the gastric juice samples taken at 7:00 am was $3.15 \mu \mathrm{g} / \mathrm{mg}$ of total protein and ranged from $1.5 \mu \mathrm{g} / \mathrm{mg}$ of protein to $4.9 \mu \mathrm{g} / \mathrm{mg}$ of protein. This means that the TFF2 protein represents between $0.15 \%$ and $0.49 \%$ of total protein when it is at its highest concentration in the gastric lumen.

COMPARISON OF TFF2 CONCENTRATION WITH PEPSIN ACTIVITY AND $\mathrm{pH}$ IN NORMAL HUMAN STOMACH

TFF2 concentrations were compared with concentrations of pepsin in gastric juice samples. Mean (SEM) pepsin activities in the 12 samples at each time point are shown in fig 6C. As with total protein, it appeared that pepsin activity was affected by the water recovery method used to position the nasogastric tube. By 1:00 pm, mean pepsin level had reached $0.89 \mathrm{mg} / \mathrm{ml}$ and thereafter varied between 0.7 and $1.1 \mathrm{mg} / \mathrm{ml}$. Mean pepsin activity was not affected by food intake and although there was a trend towards higher levels during the night, this did not reach statistical significance (fig 6C). There was no relationship between mean $\mathrm{TFF} 2$ concentrations and mean pepsin concentrations over the 24 hour period. Thus TFF2 secretion does not mirror pepsin secretion in the stomach, nor is the diurnal increase 

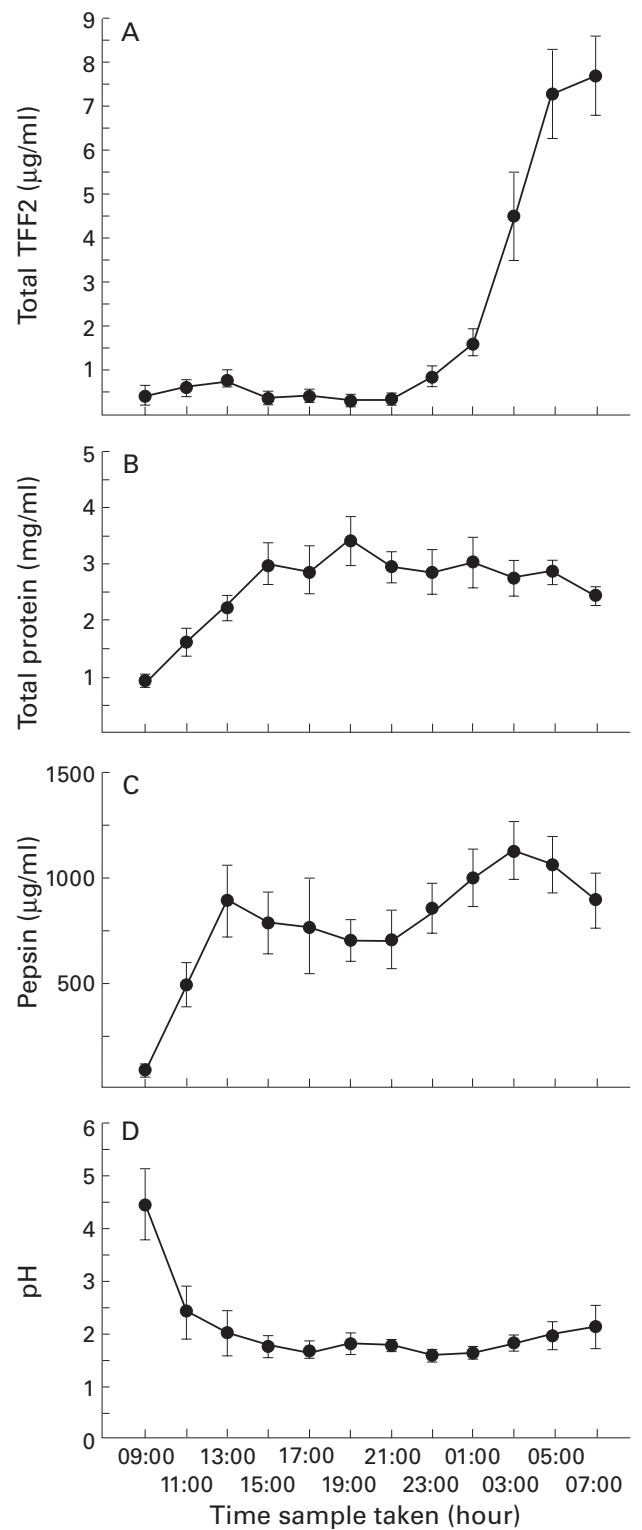

Figure 6 Comparison of total TFF2 concentration with total protein concentration, pepsin activity, and $\mathrm{pH}$ in normal human gastric juice over 24 hours. Gastric juice was collected from 12 young volunteers at two hourly intervals for 24 hours and concentrations of TFF2 $(A)$ and protein (B), pepsin activity (C), and $p H(D)$ of the

samples were measured as described in the methods. Mean (SEM) values are shown.

in TFF2 concentration facilitated by a diurnal decrease in pepsin activity.

Finally, diurnal changes in TFF2 concentration were compared with the $\mathrm{pH}$ of the gastric juice. Mean (SEM) $\mathrm{pH}$ values for the 12 gastric juice samples at each time are shown in fig 6D. The $\mathrm{pH}$ of the first samples was relatively high ( $\mathrm{pH} 4.4$ (0.67)), probably due to dilution of the gastric contents caused by the method used to position the nasogastric tube. By 11:00 am pH had fallen to $2.4(0.5)$ and thereafter it did not vary significantly. There was no discernible effect of food intake or of rest on gastric acid secretion. Diurnal changes in TFF2 secretion do not, therefore, appear to be related to gastric acid secretion.
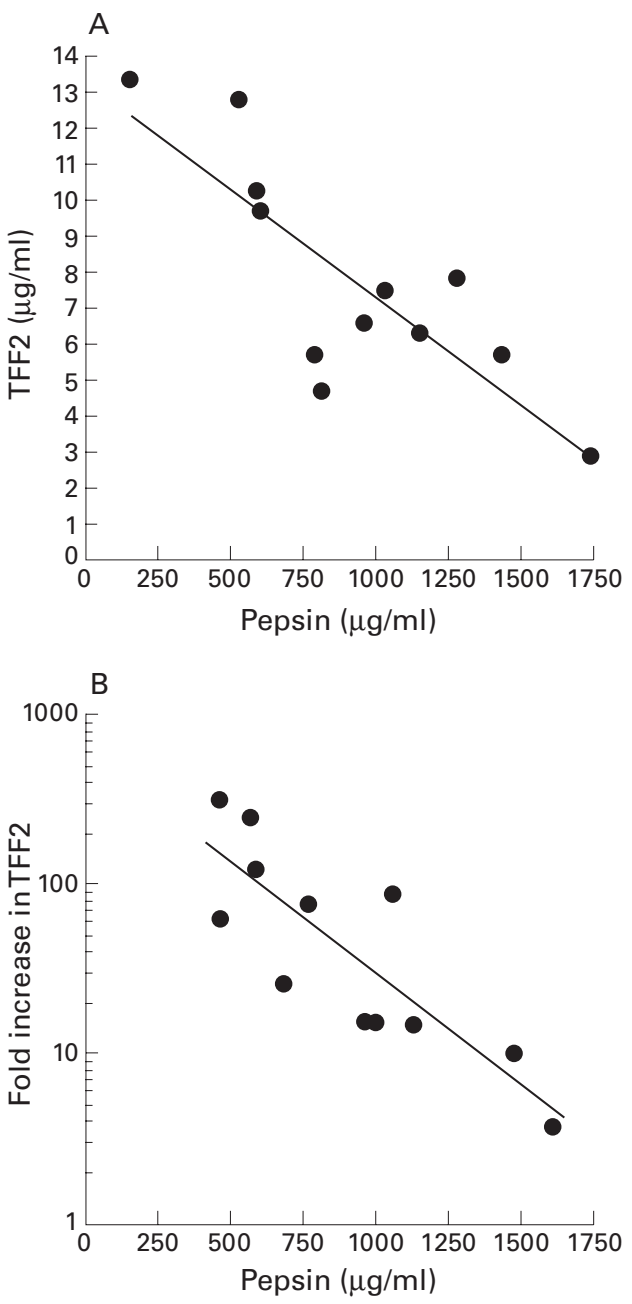

Figure 7 Relationship between pepsin activity and TFF2 concentration in individual gastric juice samples. (A) Gastric juice was collected from 12 young healthy volunteers at 7:00 am. TFF2 concentrations and pepsin activities in gastric juice were measured as described in the methods. Values for TFF2 concentration in gastric juice from each individual are shown plotted against pepsin activity. (B) Gastric juice was collected from 12 young healthy volunteers at two hourly intervals between 7:00 pm and 7:00 am. TFF2 concentrations and pepsin activities in gastric juice were measured as described in the methods. The fold increases in TFF2 concentration over this time were calculated and are plotted against the average pepsin activity for each individual.

RELATIONSHIP BETWEEN TFF2 CONCENTRATION AND PEPSIN

Changes in mean pepsin activity did not accompany the diurnal variation in mean TFF2 concentration but there was a striking inverse correlation between TFF 2 concentration and pepsin concentration in individuals. Figure 7A shows the relationship between TFF2 and pepsin concentrations at 7:00 am. This relationship was significant $(p<0.001)$ when Pearson's parametric two tailed test was used, and the $\mathrm{p}$ value was $<0.007$ with a correlation coefficient of -0.729 when Spearman's non-parametric two tailed test was used. A significant inverse correlation was also found when either the time points when TFF2 concentrations were highest were compared or when the average values at 3:00 am, 5:00 am, and 7:00 am were compared. This indicates 
that TFF2 secretion is lower in individuals with higher levels of pepsin secretion.

We also tested if the fold increase in TFF2 concentration observed during rest was related to levels of pepsin. The fold increases in TFF2 concentration between 7:00 pm and 7:00 am for each individual are shown against the average pepsin concentration during this time in fig 7B. A strong inverse correlation was observed with the greatest increase in TFF2 concentration in individuals with lower pepsin activities; Pearson's two tailed $\mathrm{p}<0.05$ and Spearman's two tailed $\mathrm{p}<0.003$ with a correlation coefficient of -0.781 .

\section{Discussion}

This is the first study of diurnal variation in concentrations of a trefoil protein. The study was designed to permit quantification of the effects of food intake and sleep on TFF2 concentrations in gastric juice during a 24 hour period. Our results show that gastric luminal TFF 2 concentrations vary dramatically over 24 hours, with highest concentrations detected during the night.

Taken together, the data suggest that the diurnal variation in gastric luminal TFF2 concentration is caused by increased secretion of TFF2. It is unlikely that the changes are due to dilution because the concentrations of other proteins, pepsin activity, and hydrogen ion concentrations do not show diurnal variation. An alternative explanation would be that the variations in TFF2 concentrations reflect differential proteolysis of TFF2. However, mean TFF2 concentrations did not show any relationship with mean pepsin concentrations over the 24 hour time course, and pepsin activity did not show diurnal variation. Proteases other than pepsin are unlikely to be responsible for the diurnal variation in TFF2 concentration because trefoil peptides, including TFF2, are characterised by resistance to proteolysis ${ }^{27}$ and TFF2 has been shown to be stable during incubation in gastric juice. ${ }^{15}$ Furthermore, in this study, TFF2 was measured by western transfer analysis, and as immunoreactive protein bands smaller than $12 \mathrm{kDa}$ were not detected there was no indication that TFF2 proteolysis occurs (fig 1B). It seems probable that the diurnal variations in gastric luminal TFF 2 concentration are due to increased synthesis and secretion.

Available evidence suggests that glycosylated TFF 2 is the major form of human TFF $2^{21}$ and that it is more potent than the non-glycosylated protein. ${ }^{15}$ The proportion of non-glycosylated TFF2 was highest during the night and early morning, which is consistent with an increase in TFF2 synthesis at night. The altered ratio is unlikely to be due to preferential proteolytic degradation of glycosylated TFF2 as glycosylation normally protects proteins from proteolysis. ${ }^{28}$ The different proportions of the two proteins probably reflect alterations in their relative rates of synthesis and secretion. The TFF2 N-glycosylation consensus sequence $\mathrm{Asn}^{15} \mathrm{Arg}^{16} \mathrm{Thr}^{17}$ is predicted to be fully glycosylated $^{29}$ and therefore the increased proportion of non-glycosylated TFF2 probably arises because the glycosylation machinery in the endoplasmic reticulum is overloaded during the synthesis and secretion of the large amounts of TFF 2 that occur during the night. ${ }^{30}$

The mechanisms that control TFF2 synthesis and secretion are unknown. It may be under the control of neurogastric peptides whose concentrations alter in response to food intake, sleep, or circadian rhythms. It is known that plasma concentrations of several gastrointestinal regulatory peptides are subject to diurnal variations ${ }^{31}$ : vasoactive intestinal polypeptide and cholecystokinin are highest during the evening and night. It has been shown that the neuropeptides somatostatin and vasoactive intestinal polypeptide, and carbachol, an analogue of acetylcholine, stimulate TFF3 mRNA synthesis by the HT-29 human colon epithelial cell line. ${ }^{32}$ If TFF2 synthesis is also regulated by these regulatory molecules, this could be the mechanism responsible for the diurnal variations in TFF2 concentrations.

TFF2 is thought to be the principal cytoprotective trefoil peptide in the stomach ${ }^{33}$ and our data suggest that it performs this role during inactivity or sleep. It is interesting that in a study of ulcer incidence in 1480 patients, a strong diurnal pattern was found with a significant trough in ulcer presentation between 4:00 am and 8:00 am when TFF2 levels are highest. $^{34}$ This suggests that TFF2 secretion increases specifically to facilitate repair of the gastric mucosa at night. In addition, our data indicate that TFF2 concentrations fall following food intake. It is possible that mucosal restitution may be suppressed during active digestion, and that TFF2 secretion may be reduced until the digestive functions of the stomach are accomplished and active restitution can resume.

This work was supported by the Cancer Research Campaign. JIS thanks the Cancer Research Campaign for a research studentship and JLN thanks Astra Foundation for a clinical research fellowship. We are grateful to Professors OFW James and A Allen for their advice and helpful discussions during the inception of this study.

1 Tomasetto C, Rio M-C, Gautier C, et al. hSP, the human homolog of pS2 protein is co-expressed with pS2 in stomach but not in breast carcinoma. EMBO f 1990;9:407-14

2 May FEB, Westley BR. Close physical linkage of the genes encoding the pNR-2/pS2 protein and human spasmolytic protein (hSP). Hum Genet 1997;99:303-7.

3 Thim L. Trefoil peptides: from structure to function. Cell Mol Life Sci 1997;53:888-903.

4 Sands BE, Podolsky DK. The trefoil peptide family. Ann Rev Physiol 1996;110:489-97.

5 Poulsom R. Trefoil peptides. Baillières Clin Gastroenterol 1996;10:113-34.

6 May FEB, Westley BR. Trefoil proteins: their role in normal and malignant cells. $\mathcal{F}$ Pathol 1997;183:4-7.

7 Gajhede M, Petersen TN, Henriksen A, et al. Pancreatic spasmolytic polypeptide (PSP): first three-dimensional structure of a member of the mammalian trefoil family of peptides. Structure 1993;1:253-62.

8 De A, Brown DG, Gorman MA, et al. Crystal structure of a disulphide-linked "trefoil" motif found in a large family of putative growth factors. Proc Natl Acad Sci USA 1994;91: 1084-8.

9 Carr MD, Bauer CJ, Gradwell MJ, et al. Solution structure of a trefoil-motif-containing cell growth factor, porcine spasmolytic protein. Proc Natl Acad Sci USA 1994;91: 2206-10.

10 Polshakov VI, Williams MA, Gargaro AR, et al. Highresolution solution structure of human $\mathrm{pNR}-2 / \mathrm{pS} 2$ : a single trefoil motif protein $\mathcal{F}$ Mol Biol 1997;267:418-32.

11 Hanby AM, Poulsom R, Singh S, et al. Spasmolytic polypeptide is a major antral peptide: distribution of the refoil peptides human spasmolytic polypeptide and pS2 in the stomach. Gastroenterology 1993;105:1110-16. 
12 Wright NA, Poulsom R, Stamp GWH, et al. Epidermal growth factor (EGF/URO) induces expression of regulatory peptides in damaged human gastrointestinal tissues. $\mathscr{f}$ Pathol

13 Wright NA, Poulsom R, Stamp GWH, et al. Trefoil peptide gene expression in gastrointestinal epithelial cells in inflammatory bowel disease. Gastroenterology 1993;104:12 20.

14 Thim L, Norris K, Norris F, et al. Purification and characterisation of the trefoil peptide human spasmolytic polypeptide (hSP) produced in yeast. FEBS Lett 1993;318 polypep

15 Playford RJ, Marchbank T, Chinery R, et al. Human spasmolytic polypeptide is a cytoprotective agent that stimulates cell migration. Gastroenterology. 1995;108:10816.

16 Dignass A, Lynch-Devaney K, Kindon H, et al. Trefoil peptides promote epithelial migration through a transforming growth factor $\beta$-independent pathway. $f$ Clin Invest growth factor
1994;94:376-83.

17 Alison MR, Chinery R, Poulsom R, et al. Experimental ulceration leads to sequential expression of spasmolytic polypeptide, intestinal trefoil factor, epidermal growth factor, and transforming growth factor alpha mRNAs in rat stomach. F Pathol 1995;175:405-14.

18 Babyatsky MW, deBeaumont M, Thim L, et al. Oral trefoil peptides protect against ethanol- and indomethacin-induced gastric injury in rats. Gastroenterology 1996;110:489-97.

19 Poulsen SS, Thulsen J, Christensen L, et al. Metabolism of oral trefoil factor 2 (TFF2) and the effect of oral and parenteral TFF2 on gastric and duodenal ulcer healing in the rat. Gut 1999;45:516-22.

20 Tanaka S, Podolsky, DK, Engel E, et al. Human spasmolytic polypeptide decreases proton permeation through gastric
mucus in vivo and vitro. Am $\mathcal{F}$ Physiol 1997;35:G1473-80.

21 May FEB, Semple JI, Newton JL, et al. The human two domain trefoil protein, TFF2, is glycosylated in vivo in the stomach. Gut 2000;46:454-9.

22 Baron JH. History, methodology and interpretation. Clinical tests of gastric secretion. London: Macmillan, 1978.
23 Chadwick MP, Westley BR, May FEB. Homodimerization and hetero-oligomerization of the single-domain trefoil protein pNR-2/pS2 through cysteine 58. Biochem $\mathcal{F}$

24 Piggott NH, Henry JA, May FEB, et al. Antipeptide antibodies against the pNR-2 oestrogen-regulated protein of human breast cancer cells and detection of pNR-2 expression in normal tissues by immunohistochemistry. $\mathcal{F}$ Pathol 1991;63:95-104.

25 Hutton DA, Allen A, Pearson JP, et al. Separation of pepsins in human gastric juice: analysis of proteolytic and mucolytic activity. Biochem Soc Trans 1986;14:735-6.

26 Smith PK, Krohn RI, Hermanson GT, et al. Measurement of protein using bicinchoninic acid. Anal Biochem 1985; 150:76-85.

27 Jørgensen KD, Diamant B, Jørgensen KH, et al. Pancreatic spasmolytic polypeptide (PSP): III. Pharmacology of a new porcine pancreatic polypeptide with spasmolytic and porcine pancreatic polypeptide with spasmolytic and
gastric acid secretion inhibitory effects. Regul Pept 1982;3: gastric acid $231-43$.

28 Rudd PM, Fortune FM, Patel T, et al. Glycoforms modify the dynamic stability and functional activity of an enzyme. the dynamic stability and funct
Biochemistry 1994;33:17-22.

29 Shakin-Eshleman SE, Spitalnik SL, Kasturi L. The amino acid at the X position of an Asn-X-Ser sequon is an important determinant of N-linked core-glycosylation efficiency. f Biol Chem 1996;271:6363-6.

30 Rudd PM, Dwek RA. Glycosylation: heterogeneity and the 3D structure of proteins. Crit Rev Biochem Mol Biol 1997;32:1-100.

31 Jorde R, Burhol PG. Diurnal profiles of gastrointestinal regulatory peptides. Scand F Gastroenterol 1985;20:1-4.

32 Ogata H, Podolsky DK. Trefoil peptide expression and secretion is regulated by neuropeptides and acetylcholine. Am 7 Physiol 1997;273:G348-54.

33 Wong WM, Poulsom R, Wright NA. Trefoil peptides. Gut $1999 ; 44: 890-5$.

34 Svanes C, Sothern RB, Sørbye H. Rhythmic patterns in incidence of peptic ulcer perforation over 5.5 decades in Norway. Chronobiol Int 1998:15:241-64.

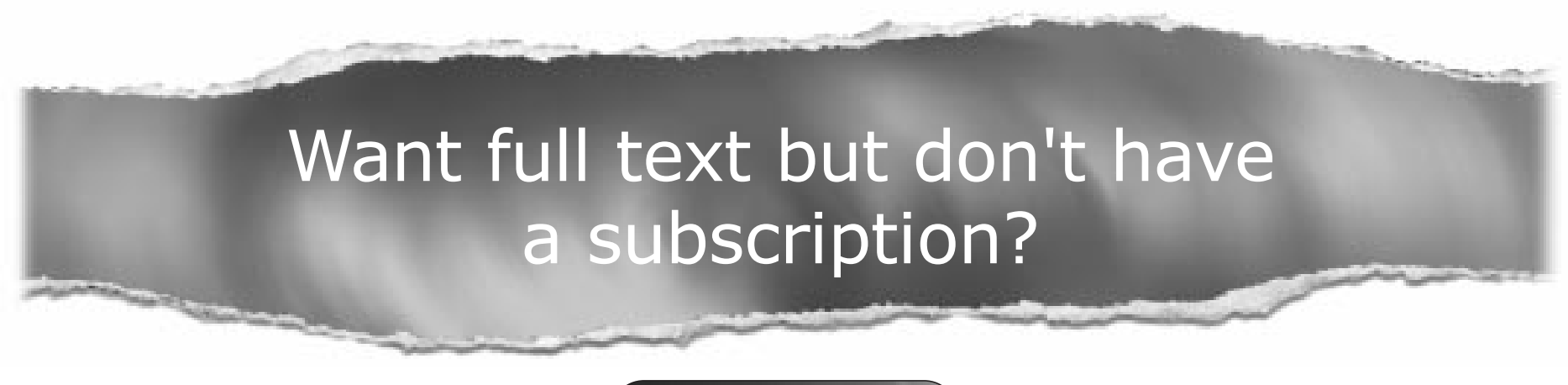

\section{Pay per view}

For just $\$ 8$ you can purchase the full text of individual articles using our secure online ordering service. You will have access to the full text of the relevant article for 48 hours during which time you may download and print the pdf file for personal use.

\section{www.gutjnl.com}

